\title{
Effect of Chemical Pretreatments on the Physical Properties of Kiwi
}

\author{
Raquel P. F. Guiné \\ Department of Food Industry, CI\&DETS/ESAV, Polytechnic Institute of Viseu, Viseu, Portugal \\ Email: raquelguine@esav.ipv.pt \\ Ana Rita F. Roque \\ Department of Food Industry, Agrarian School of Viseu, Viseu, Portugal \\ Email: ritafroque@gmail.com \\ Fábio F. A. Seiça and Cátia E. O. Batista \\ Kiwicoop - Cooperativa Frutícola da Bairrada, Oliveira do Bairro, Portugal \\ Email: \{qualidade, qualidade\}@kiwicoop.com
}

\begin{abstract}
In this work the effect of pre-treatments on the physical properties of fresh kiwi was studied. For that, a set of tests using chemical pretreatments was used, in which the samples were subjected to aqueous solutions of ascorbic acid and potassium metabisulfite at concentrations of $0.25 \%$ and $1 \%(w / v)$ for periods of 30 and 60 minutes, in order to understand the implications of the treatments in the color and texture of the kiwi as compared to its original properties. The results showed that the kiwi treated with ascorbic acid changed its color very intensively when compared to the fresh product, and this trend was intensified after storage. Contrarily, when potassium metabisulfite was used, the changes in color were quite negligible right after the treatment and even lower after the storage period of 6 days under refrigeration. After the treatments with both solutions, the kiwi texture was drastically changed, diminishing hardness considerably and increasing elasticity for all treatments. The same could be observed after six days of refrigeration.
\end{abstract}

Index Terms - chemical pretreatment, kiwifruit, color, texture, ascorbic acid, potassium metabisulfite

\section{INTRODUCTION}

The kiwifruit (also shortened to kiwi) is the edible berry of a woody vine in the genus Actinidia, being the 'Hayward' the most common kiwi cultivar [1]. Botanically the kiwifruit develops from a multicarpelar ovary and is classified as a berry. The peel is light brownish green and completely covered by small filaments. The pulp (pericarp) surrounding the central zone of the fruit (columella) is bright green color having included hundreds of small black seeds [2].

The Actinidia is native of China, especially the forests and valleys near the river Yang-Tse-Kiang. In the early twentieth century the culture was introduced in New Zealand, which has become the largest producer and exporter up to the 80s last century. Other countries with

Manuscript received January 7, 2016; revised August 11, 2016. similar climate started to produce kiwi and thus commercial production expanded throughout America and Europe. The Actinidia (cultivar 'Hayward') was introduced in Portugal in 1973, having gained growing interest in Portugal, especially in the regions of between Douro and Minho and Beira Litoral, which have suitable edafoclimate conditions for their proper development [3].

Kiwi is very nutritious and rich in bioactive components, being particularly rich in vitamin $\mathrm{C}$ (one kiwi equivalent to five lemons), minerals ( $\mathrm{Na}, \mathrm{K}, \mathrm{Ca}, \mathrm{Mg}$, $\mathrm{Mn}, \mathrm{Fe}, \mathrm{Cu}, \mathrm{Zn}$ ) and organic hydroxiacids that are involved in the acid-base balance of the body [4].

Due to its nutritional and medicinal properties, in ancient times, in China, kiwifruit was used as a remedy for treating several health disorders, including digestive disturbances, rheumatism, and dyspepsia. In a more recent past kiwi has gained worldwide popularity since consumers associated the consumption of kiwi fruits with potential health effects. Kiwifruits have several compounds with antioxidant properties, including ascorbic acid, carotenoids and polyphenols with strong antioxidant capacity. Increased consumption of these fruits protects against cardiovascular diseases, helps decrease of lipids in blood and improves gastrointestinal laxation, due to the content in dietary fiber [4], [1], [5][9].

The kiwi cultivar 'Hayward' has an unusual climatic behavior: it undergoes ethylene autocatalysis during maturation at ambient temperature, but not at temperatures below $10{ }^{\circ} \mathrm{C}$, thus allowing prolonged storage and marketing throughout the year [3].

The main causes of deterioration of kiwifruit are premature softening, high ethylene content, water loss, and physiological and pathological disorders. Among them, the softening and the presence of ethylene in the storage environment cause great problems for the Kiwi industry, as well as the presence of Botrytis. Kiwis are stored at a temperature of $0{ }^{\circ} \mathrm{C}$ and the relative humidity should be maintained at about $90-95 \%$ to avoid loss of 
weight, which may be high due to the structure of the epidermis. Kiwis with water losses of over $4 \%$ are unmarketable [10].

Minimally processed products are defined as vegetables and fruits ready to be consumed after processes such as cutting, washing, drying, packing and cold storage. Minimally processed fruits should maintain their attributes and their quality similar to those of fresh products. They are very popular nowadays because they target a demanding consumer group with less time to devote to the kitchen and preparing meals. However, minimal processing alters the integrity of fruit and induces wounding stress and spoilage. Physical damage or wounding together with other mechanical injuries results in increased respiration rates and ethylene production within minutes. During storage such products have a very limited shelf life, typically the storage period is 4-6 days at $4^{\circ} \mathrm{C}[10]-[12]$.

The goals of this work were to evaluate the possibility of extending the shelf life of minimally processed kiwis by submitting them to chemical pre-treatments with variable chemicals, concentrations and times, and evaluating the effect on texture and color of the final products right after treatments and after 6 days of storage under refrigeration.

\section{MATERIALS AND METHODS}

\section{A. Samples}

The samples used were from kiwifruits harvested in the Littoral center of Portugal from the variety 'Hayward', caliber 27 and class I. The fruits were peeled and cut into slices with a thickness of $5 \mathrm{~mm}$.

\section{B. Reagents}

The reagents used were the $\mathrm{L}(+)$-ascorbic acid (E220), whose chemical formula is $\mathrm{C}_{6} \mathrm{H}_{8} \mathrm{O}_{6}$, and the potassium metabisulfite, with chemical formula $\mathrm{K}_{2} \mathrm{~S}_{2} \mathrm{O}_{5}$ (E224), ta 97\% extra pure. Both additives are permitted for foodstuffs in accordance with Portuguese Law No. 94/2010 of 29 July: E220 - ascorbic acid and E224 potassium metabisulfite.

\section{Experimental Procedure for Pretreatments}

The kiwi samples were dipped into an aqueous solution of each of the chemicals (ascorbic acid and potassium metabisulfite) at concentrations of $1 \%$ and $0.25 \%(\mathrm{~m} / \mathrm{v})$ for variables times: 30 and 60 minutes, as shown in Fig. 1. The thermostatic bath was kept at constant temperature of $25^{\circ} \mathrm{C}$ during all experiments.

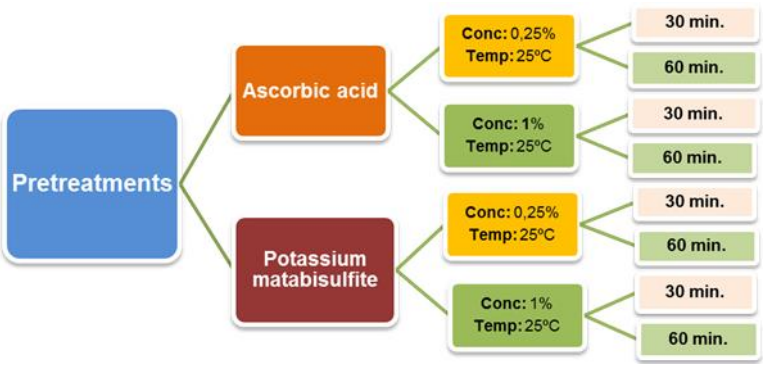

Figure 1. Experimental design for the pretreatment applied to the kiwi.

\section{Analysis of Color}

Before and after the pretreatments the kiwi was analyzed for its color, using a handheld tristimulus colorimeter (Chroma Meter - CR-400, Konica Minolta) calibrated with a white standard tile. A CIE standard illuminant D65 was used to determine the CIELab Cartesian coordinates: $\mathrm{L}^{*}, \mathrm{a}^{*}$ and $\mathrm{b}^{*}$. $\mathrm{L}^{*}$ denotes lightness or brightness, ranging from zero (black) to 100 (white), $\mathrm{a}^{*}$ and $\mathrm{b}^{*}$ are the opposing color coordinates, with $\mathrm{a}^{*}$ ranging from -60 (green) to +60 (red) and $\mathrm{b}^{*}$ ranging from -60 (blue) to +60 (yellow) [13].

The measurements were done in the fresh sample, in the treated samples right after the treatments and after 6 days of storage under refrigeration.

The total color change $(\Delta \mathrm{E})$ was considered for evaluating the overall color difference between a treated sample and the fresh kiwi (designated with an index 0) on equation (1):

$$
\Delta \mathrm{E}=\sqrt{\left(\mathrm{L}_{0}-\mathrm{L}\right)^{2}+\left(\mathrm{a}_{0}-\mathrm{a}\right)^{2}+\left(\mathrm{b}_{0}-\mathrm{b}\right)^{2}}
$$

The Fresh kiwi was used as the reference and a larger $\Delta \mathrm{E}$ denotes a greater color change from the reference material.

\section{E. Evaluation of Texture}

Texture Profile Analysis (TPA) to all the samples was performed using a Texture Analyser (model TA.XT.Plus) The texture profile analysis was carried out by two compression cycles, with a 5 seconds interval, between parallel plates using a flat $75 \mathrm{~mm}$ diameter plunger $(\mathrm{P} / 75)$ and a $5 \mathrm{~kg}$ force load cell. The test speed was $1.5 \mathrm{~mm} / \mathrm{s}$.

The measurements were done in the fresh sample, in the treated samples right after the treatments and after 6 days of storage under refrigeration.

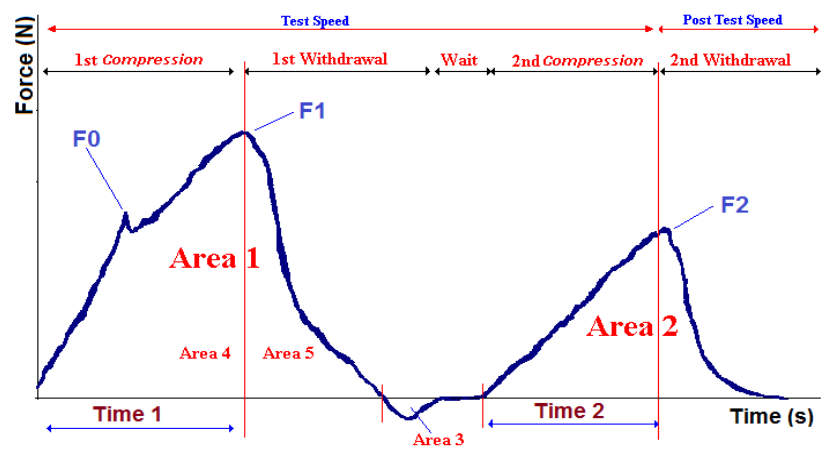

Figure 2. Texture profile analysis calculations.

The textural properties: hardness, springiness, cohesiveness, and chewiness were calculated after equations (2) to (4) (see Fig. 2) [14], [15]:

$$
\begin{gathered}
\text { Hardness }(\mathrm{N})=\mathrm{F} 1 \\
\text { Adhesiveness }(\mathrm{N} . \mathrm{s})=\text { Area3 } \\
\text { Fracturability }(\mathrm{N})=\mathrm{F} 0 \\
\text { Cohesiveness }=\text { Area2/Area1 } \\
\text { Springiness }(\%)=\text { Time2/Time1 } * 100
\end{gathered}
$$

Chewiness $(\mathrm{N})=\mathrm{F} 1 *$ Time $2 /$ Time $1 *$ Area2/Area 1 


\section{RESULTS AND DISCUSSION}

\section{A. Color}

Fig. 3 shows the values of lightness for the different samples analyzed, i.e., in fresh, immediately after the different pretreatments and after a storage of 6 days under refrigeration. The treatment with Ascorbic Acid (AA) induced a reduction in lightness, regardless of concentration in time and this trend continued after 6 days of storage, so that this chemical agent induced a darkening of the samples. However, when Potassium Metabisulfite (PMB) was used, the lightness was maintained or increased, in comparison to the fresh sample. The lightness of the fresh kiwi ranges between 44.3 and 61.6 and Nunes-Damaceno et al. [16] registered values in the range 39.5-45.6, for fresh kiwi, depending on the production mode, with a value of 43.9 for conventional agriculture, which is close to the value encountered in this work for the fresh sample used for the tests faith ascorbic acid.

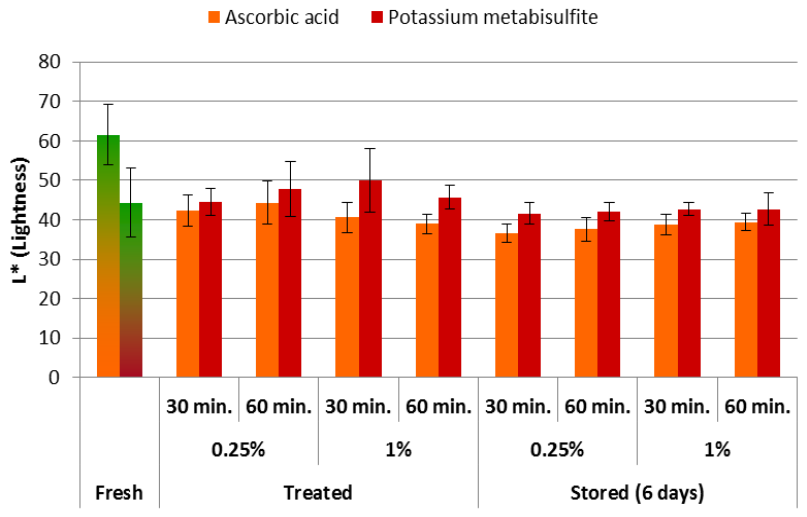

Figure 3. Lightness ( $\left.\mathrm{L}^{*}\right)$ of the different samples analyzed.

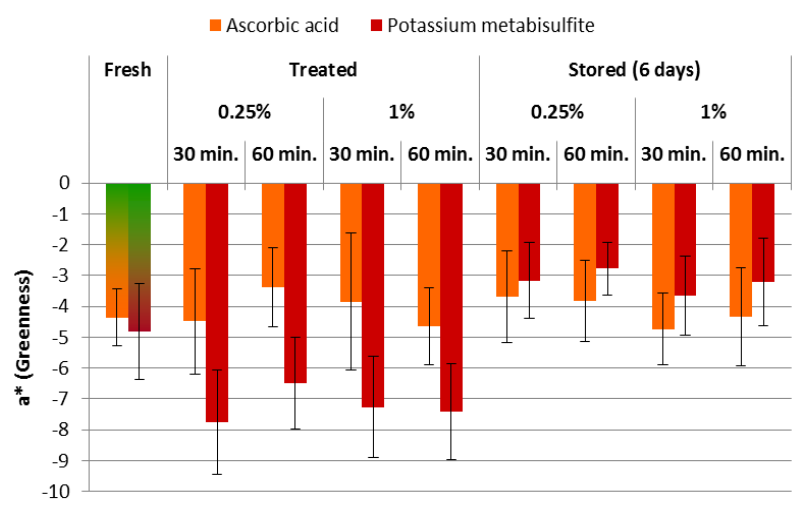

Figure 4. Greenness ( $\left.a^{*}\right)$ of the different samples analyzed.

In Fig. 4 are shown the results obtained for the color coordinate $\mathrm{a}^{*}$, referring to greenness (negative values of $a^{*}$ indicate a green color). The results indicate that ascorbic acid has a different effect on the green color, depending on time and concentration, allowing obtaining a more intense green for the treatments $30 \mathrm{~min}$ with $0.25 \%$ and also $60 \mathrm{~min}$. with $1 \% \mathrm{AA}$. Contrarily, the treatments with metabisulfite allowed the intensification of the green color (more negative values) for all concentrations and all times, thus originating a more appealing product after the treatment. However, unfortunately this effect does not persist after the cold storage for 6 days, when the greenness falls abruptly, even more than with ascorbic acid. The values of $a^{*}$ for the fresh kiwi varied between -4.8 and -4.4 , being very similar to the value found by Nunes-Damaceno et al. [16] for fresh kiwi produced in conventional farming, -4.6.

The results for the color coordinate $b^{*}$, which correspond $\mathrm{s}$ to yellow when the values are positive, are shown in Fig. 5. In general the treatments with ascorbic acid induced a decrease in yellowness when compared to the fresh sample, with exception for the treatment of 60 min. with $1 \%$ AA. However, in this case, the cold storage did not seem to affect the yellow color of the kiwi treated with AA. Regarding the treatments with metabisulfite, the yellowness was quite unchanged for all treatments used, and the same trend was maintained after storage. The $b^{*}$ for the fresh kiwi was in the range 17.4-20.0, being very close to that reported by Nunes-Damaceno et al. [16] for fresh kiwi from different production systems: 19.2-23.2.

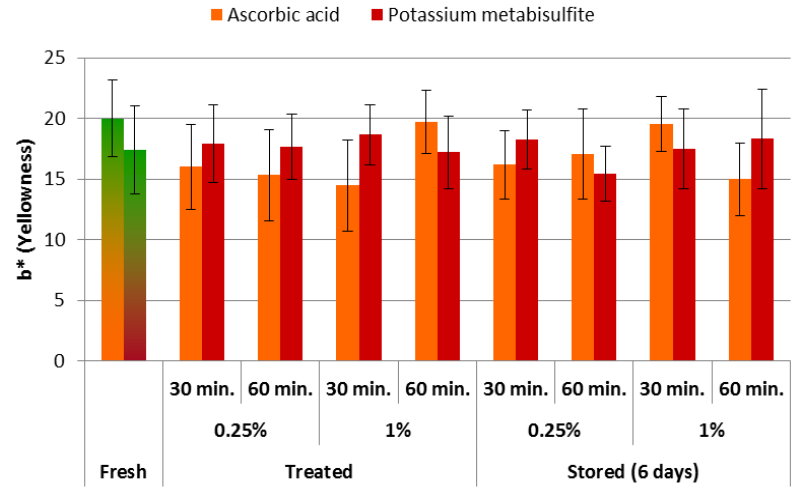

Figure 5. Yellowness $\left(b^{*}\right)$ of the different samples analyzed.

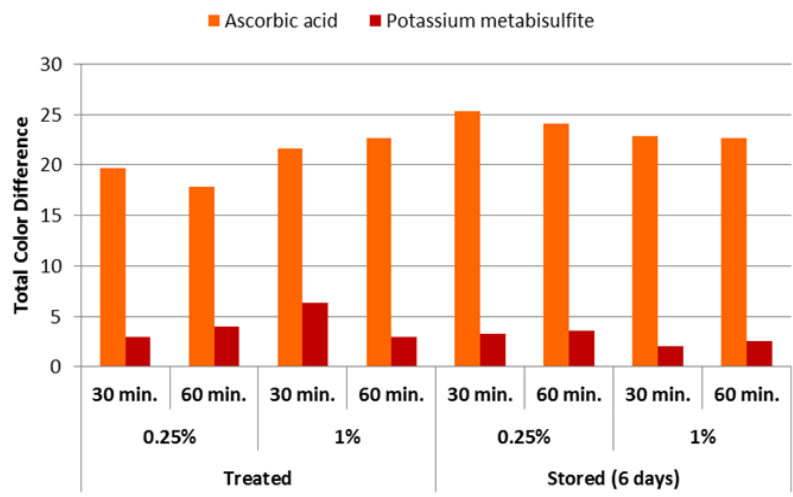

Figure 6. Total color difference $(\Delta \mathrm{E})$ of the samples analyzed.

The total color difference $(\Delta \mathrm{E})$ presented in Fig. 6 is a good indicator of the overall difference between a sample and that taken as reference. The results confirm that globally, the treatments with AA induce much higher changes in the color of the kiwi as compared to the freshly cut product than the treatments with MBS. In the case of using AA at a concentration of $0.25 \%$ for 30 minutes, the color difference may go up to 25.3 , and the lowest color difference is still very high: 17.9 for a. $25 \%$ 
during $60 \mathrm{~min}$. In the case of MBS, the highest color difference is 6.4 (for $30 \mathrm{~min}$. at $1 \%$ ) and all others are lower, being the lowest color difference equal to 2.0 (30 min at $1 \%$, after 6 days of storage). The trend in total color difference did not vary when the samples were analyzed after 6 days of storage.

\section{B. Texture}

The hardness represents the force to compress between molars, bite through with incisors, compress between tongue and palate. Fig. 7 shows the hardness for the samples analyzed and the results indicate that all treatments induced a very pronounced reduction in hardness, varying from $64 \%$ for (AA-1\%-60min) to $95 \%$ for (MBS-1\%-60min-stored). The hardness of the fresh samples varied from 79.5 to $89.5 \mathrm{~N}$. The results further show that the storage induces a reduction in hardness for all treatments. Nunes-Damaceno et al. [16] reported values of about $14 \mathrm{~N}$ for the firmness of kiwi from conventional agriculture and $15 \mathrm{~N}$ for organic kiwi, which are much lower than in the present study. This can be due to different maturity stages.

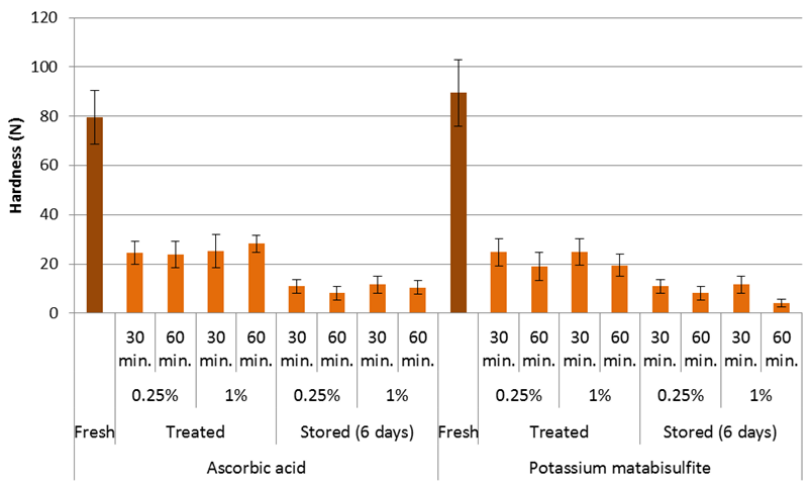

Figure 7. Hardness of the samples analyzed.

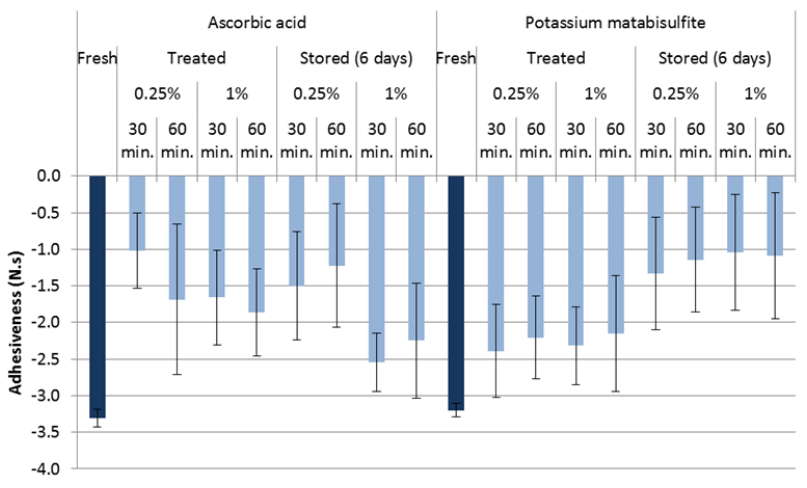

Figure 8. Adhesiveness of the samples analyzed.

The results in Fig. 8 refer to the adhesiveness, which is the force required to remove the material that adheres to a specific surface such as the lips, palate or teeth. The adhesiveness is a negative area, as shown in Fig. 2, and in this case the absolute values of adhesiveness are not high, meaning that, although the kiwi samples have some adhesives, it is not very meaningful (maximum of about 3.5 N.s for the fresh samples). The adhesiveness was reduced with all treatments (corresponding to higher values, or lower absolute values) for the treatments with both chemicals: AA or MBS. While when AA is used the results are variables, in the case of the MBS, the adhesiveness of the samples right after treatments is more or less similar, and decreases in all cases after 6 days of cold storage.

The graph in Fig. 9 refers to fracturability, which occurs where the plot has its first significant peak corresponding to where the force falls off during the probe's first compression of the product. It indicates the first point leading to rupture of the sample and not all products present such behavior. The faracturability of the fresh samples was about $25 \mathrm{~N}$, and again the treatments applied in all cases reduced significantly the fracturability (49\% for AA and 58\% for MBS), being this reduction even more pronounced after the 6 days of cold storage (52\% for AA and $668 \%$ for MBS).

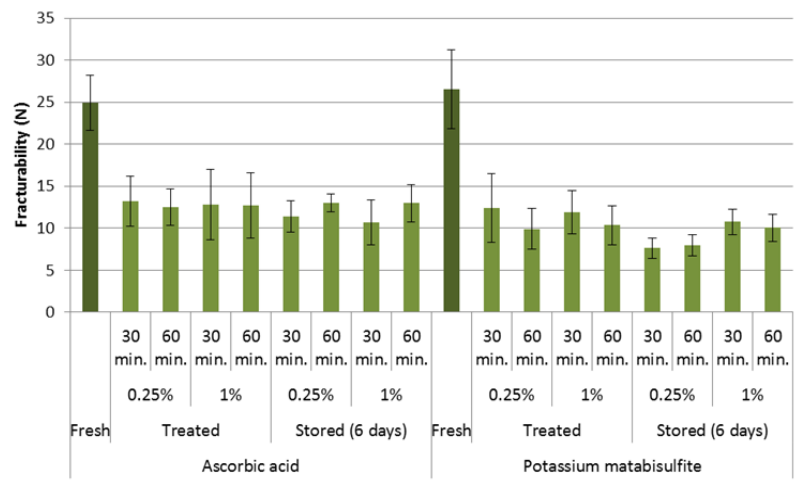

Figure 9. Fracturability of the samples analyzed.

The cohesiveness is how well the product withstands a second deformation relative to how it behaved under the first deformation. The cohesiveness of the fresh kiwi was 0.43 and the samples treated both with AA and MBS diminished choosiness right after the treatment, but increased again after the storage period (Fig. 10). This is expected, because the samples were still wet, although the excess of water was removed, when they were analyzed after the treatments, and this diminishes the internal forces keeping the sample cohesive. On the other hand, after 6 days, the sample became more dehydrated, thus increasing its integrity.

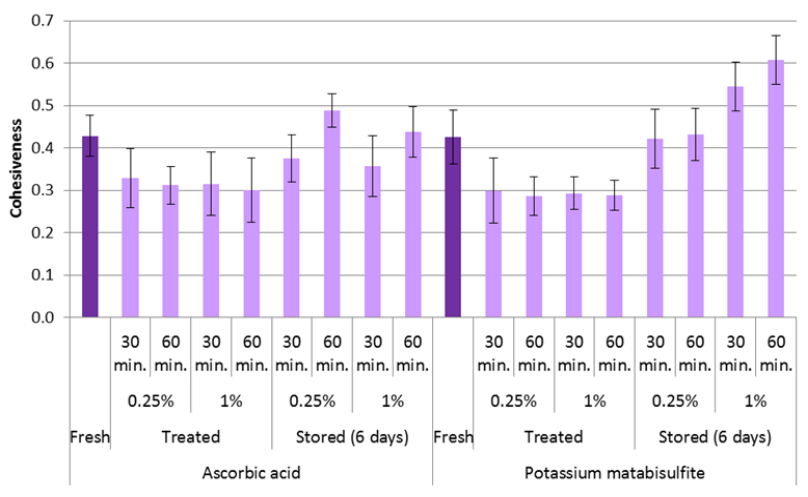

Figure 10. Cohesiveness of the samples analyzed.

The elasticity how well a product physically springs back after it has been deformed during the first compression. The elasticity of the fresh samples was $44 \%$ 
and increased with the treatments applied (37\% for AA and $36 \%$ for MBS, on average) and even more after the storage ( $46 \%$ for AA and $89 \%$ for MBS, on average) (Fig. $11)$.

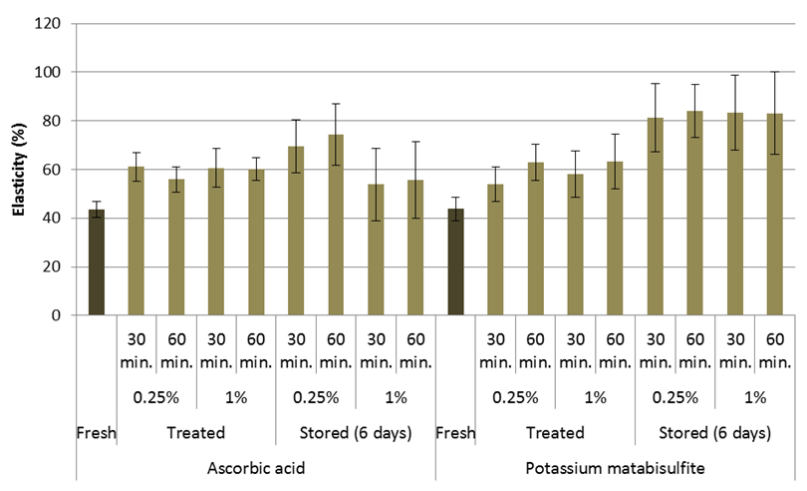

Figure 11. Elasticity of the samples analyzed.

The chewiness corresponds to the effort needed to masticate the sample to a consistency suitable for swallowing. Fig. 12 shows the cohesiveness for the samples analyzed. The chewiness of the fresh samples varied between 15 and $17 \mathrm{~N}$ and the results indicate that all treatments induced a very pronounced reduction in chewiness, varying from $66 \%$ for (AA-1\%-60min) to $88 \%$ for (MBS-0.25\%-30min-stored) and for (MBS-1\%60 min-stored). In general the reduction after the treatments was about $69 \%$ and $78 \%$ (for AA and MBS, respectively) and this reduction was even higher after the cold storage for 6 days ( $83 \%$ for AA and $86 \%$ for MBS).

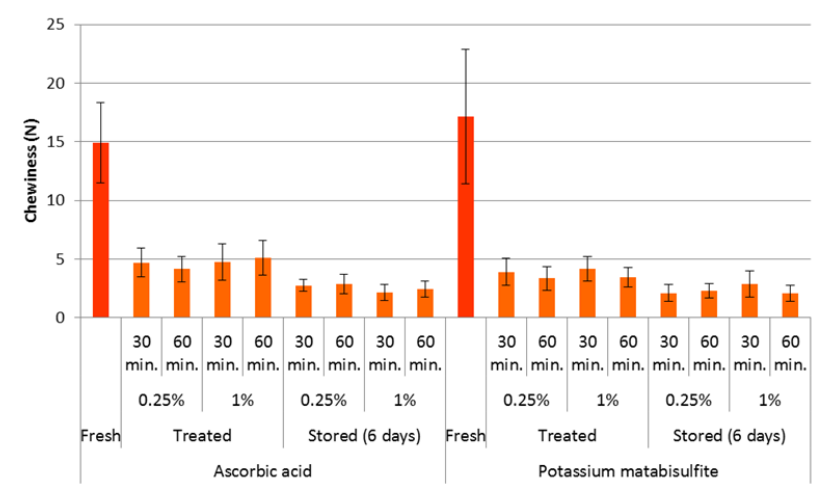

Figure 12. Chewiness of the samples analyzed.

\section{CONCLUSIONS}

The present work allowed concluding that while the treatments applied could have a positive effect on the color of kiwi, regarding its texture, the consequences were drastic. In fact, it was possible to extend the shelf life of kiwis up to 6 days in cold if they were treated with potassium matabisulfite with just a very slight loss of color, however, if the treatments were made with ascorbic acid, the changes in color would be quite intense. Nevertheless, the texture was found to very much affected by all treatments, regardless of the chemical used, the concentration or the soaking time.

In view of the results obtained some new studies would be adequate to complement this work, namely the study of alternative methods of application of the pretreatments, such as spaying with the solutions instead of dipping the kiwi samples into them.

\section{ACKNOWLEDGMENT}

The authors wish to thank CI\&DETS Research Centre and Polytechnic Institute of Viseu for the financial support to disseminate this work.

\section{REFERENCES}

[1] Y. S. Park, et al., "Bioactive compounds and the antioxidant capacity in new kiwi fruit cultivars," Food Chemistry, vol. 165, pp. 354-361, Dec. 2014.

[2] S. M. Barros, Metedologias Integradas Para a Conservação de Kiwi Minimamente Processados. Relatório Final de Doutoramento, Lisboa, Portugal: Instituto Superior de Agronomia, 2007.

[3] D. Antunes, Kiwi - Da Produção à Comercialização, Loulé, Portugal: Ciências da Terra, 2008.

[4] A. Peticila, G. V. Scaeteanu, R. Madjar, F. Stanica, and A. Asanica, "Fertilization effect on mineral nutrition of Actinidia deliciosa (kiwi) cultivated on different substrates," Agriculture and Agricultural Science Procedia, vol. 6, pp. 132-138, 2015.

[5] Y. S. Park, et al., "The effects of ethylene treatment on the bioactivity of conventional and organic growing 'Hayward' kiwi fruit," Scientia Horticulturae, vol. 164, pp. 589-595, Dec. 2013.

[6] C. S. Gammon, R. Kruger, A. M. Minihane, C. A. Conlon, P. R. von Hurst, and W. Stonehouse, "Kiwifruit consumption favourably affects plasma lipids in a randomised controlled trial in hypercholesterolaemic men," Br. J. Nutr., vol. 109, no. 12, pp. 2208-2218, Jun. 2013.

[7] T. Krupa, P. Latocha, and A. Liwińska, "Changes of physicochemical quality, phenolics and vitamin $\mathrm{C}$ content in hardy kiwifruit (Actinidia arguta and its hybrid) during storage," Scientia Horticulturae, 2011.

[8] M. Mikulic-Petkovsek, V. Schmitzer, A. Slatnar, F. Stampar, and R. Veberic, "Composition of sugars, organic acids, and total phenolics in 25 wild or cultivated berry species," J. Food Sci., vol. 77 , no. 10, pp. C1064-1070, Oct. 2012.

[9] M. Leontowicz, et al., "Bioactivity and bioavailability of minerals in rats loaded with cholesterol and kiwi fruit," Microchemical Journal, vol. 114, pp. 148-154, May 2014

[10] A. R. F. Roque, Aproveitamento Integral do Kiwi - IV Gama. Trabalho Final de Licenciatura em Engenharia Alimentar, Viseu, Portugal: Escola Superior Agrária de Viseu, 2015.

[11] M. Mastromatteo, M. Mastromatteo, A. Conte, and M. A. D. Nobile, "Combined effect of active coating and MAP to prolong the shelf life of minimally processed kiwifruit (Actinidia deliciosa cv. Hayward)," Food Research International, vol. 44, no. 5, pp. 1224-1230, Jun. 2011.

[12] S. Beirão-da-Costa, A. Steiner, L. Correia, J. Empis, and M. Moldão-Martins, "Effects of maturity stage and mild heat treatments on quality of minimally processed kiwifruit," Journal of Food Engineering, vol. 76, no. 4, pp. 616-625, Oct. 2006.

[13] R. P. F. Guiné and M. J. Barroca, "Quantification of browning kinetics and colour change for quince (Cydonia oblonga Mill.) exposed to atmospheric conditions," Agricultural Engineering International: CIGR Journal, vol. 16, no. 4, pp. 285-298, Dec. 2014.

[14] R. P. F. Guiné and M. J. Barroca, "Effect of drying treatments on texture and color of vegetables (pumpkin and green pepper)," Food and Bioproducts Processing, vol. 90, no. 1, pp. 58-63, Jan. 2012.

[15] S. C. R. V. L. Santos, R. P. F. Guiné, and A. I. A. Barros, "Influence of drying on the properties of pears of the Rocha variety (Pyrus communis)," International Journal of Food Engineering, vol. 9, no. 2, Jan. 2013.

[16] M. Nunes-Damaceno, N. Muñoz-Ferreiro, M. A. RomeroRodríguez, and M. L. Vázquez-Odériz, "A comparison of kiwi fruit from conventional, integrated and organic production systems," LWT - Food Science and Technology, vol. 54, no. 1, pp. 291-297, Nov. 2013. 


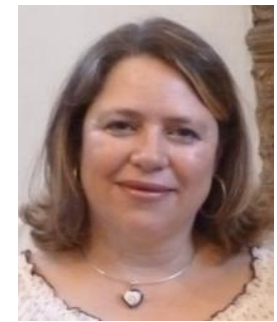

Raquel P. F. Guiné has a degree in Chemical Engineering (1991), a MsC in Engineering Science (1997) and a $\mathrm{PhD}$ in Chemical Engineering (2005), all at the Faculty of Science and Technology of the University of Coimbra (Portugal). She has a Teaching Habilitation in Food Science (2015) from the University of Algarve (Portugal). She has a Certificate of Proficiency in English (CPE, 1986) by the University of Cambridge (United Kingdom). Her major fields of study include food engineering and food processing.

She has been a University Teacher since 1994, being presently a Coordinating Professor with Habilitation at the Food Industry Department in Polytechnic Institute of Viseu - IPV (Portugal). Has been President of the Scientific Board; President of the Assembly of Representatives; Director of Licence Course, Director of MsC Course, and presently is Head of Department all at ESAV, IPV (Portugal). Is author of 14 books, 34 chapters, 142 research papers and 171 conference proceedings. Has authored 104 oral communications and 94 posters presented at scientific conferences. Selected published books: Vitamin C. Dietary Sources, Technology, Daily Requirements and
Symptoms of Deficiency (New York, USA: Nova Science Publishers, 2013); Engineering Aspects of Cereal and Cereal-Based Products (Boca Raton, USA: CRC Press, 2013); Handbook of Fruit and Vegetable Flavors (New York, USA: John Wiley \& Sons, 2010). Her research interests include areas such as food engineering, food processing, food properties, food chemistry and nutrition.

Prof. Guiné is a member of the Portuguese Chemical Society (SPQ) and Asia-Pacific Chemical, Biological \& Environmental Engineering Society (CBEES). Awards: 2011 - Research Project distinguished (Project lead by her); 2011 - Certificate of Excellence of paper published in Food and Bioproducts Processing in 2010; 2013 - First Prize in the National Contest sponsored by the CAP relative to a new food developed; 2015 - Certificate of Excellence for oral communication presented at 2nd International Conference on Food and Nutrition Technology (ICFNT 2015), Jeju Island, Republic of Korea; 2015 - Best Scientific Paper CI\&DETS Published in 2014, in the Research Group in Food, Agrarian and Veterinary Sciences; $2016-$ Certificate of Best Oral Presentation for communication presented at the 2nd International Conference on Food and Agricultural Engineering (ICFAE 2016), Copenhagen, Denmark; 2016 - Third Prize in the Regional Contest Poliempreende relative to a new entrepreneurship idea. (URL: www.raquelguine.pt) 